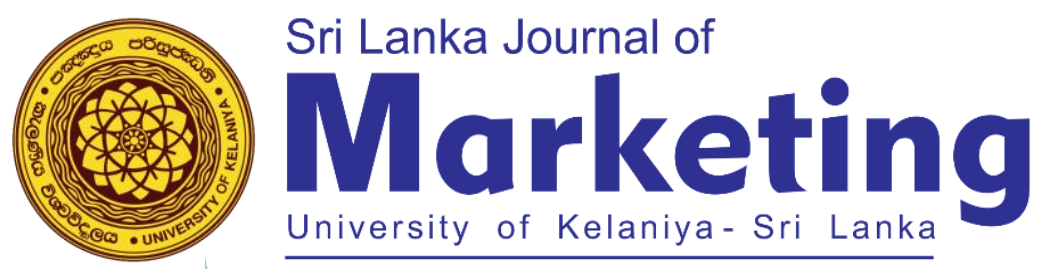

\title{
Decision Making Styles of Sri Lankan Millennial: Are They Different?
}

\author{
Lakshika, V. G. P. \\ Lecture, University of Sri Jayewardenepura, Sri Lanka \\ pavani@sjp.ac.lk \\ Ahzan, M. J. M. F. \\ Senior Lecturer, University of Colombo, Sri Lanka \\ fazeelaja@mkt.cmb.ac.lk
}

\begin{abstract}
At present consumer decision making is more complex and difficult but far more vitally in it is important than the past as the consumers today are thorough consumers. Therefore, consumer decision-making styles have become one of the most popular and interesting areas of research in the marketing and behavioral sciences of academia. Besides, in the modern marketing era, Millennial has become one of the major interesting research subject due to their unique characteristics. Therefore, the aim of this study is to develop a more rigorous understanding of the Sri Lankan millennial decision-making styles. The research philosophy of the current study is a positivist research paradigm and follows a deductive approach and survey strategy. Convenience sampling technique was used to draw the sample and the sample size was 385. The study extracted seven factors from the original Consumer Styles Inventory (CSI) scale through an exploratory factor analysis and found that Sri Lankan millennial has seven decision making styles namely Perfectionist Conscious, Habitual \& Brand Loyal Conscious, Novelty Fashion Conscious, Brand Conscious, Hedonistic \& Recreational Conscious, Confused by over choice and Impulsive Consumer. Further it revealed Price - conscious decision - making style did not appear among the Sri Lankan Millennial where Sri Lankan millennial are highly perfectionist conscious consumers. Based on the findings, study proposes several theoretical and practical implications along with direction for the future research.
\end{abstract}

Keywords: Consumer Decision-Making Styles, Consumer Styles Inventory, Millennial 


\section{INTRODUCTION}

In today's continuously changing and dynamic environment, it has become essential for marketing managers to clearly understand and predict how different types of consumers behave when purchasing, consuming and disposing different products and services in order to fulfill their needs.

Therefore, researchers have shown an increased interest in studying consumer behavior which comprises an endless and diverse field such as decision making, internal influences, and external influences on the consumer (Schiffman, Hansen \& Kinuk, 2007). Among those fields, consumer decision making styles have become one of the most popular and interesting areas of research among marketing and behavioral sciences academics due to high importance placed on the concept in marketing practices (Bae, Pyun, \& Lee, 2010; Wanninayake, 2014).

At present consumer decision making is more complex and difficult but far more vitally in it is important than the past (Hafstrom, Chae, Chung, Hafstrom, \& Chae, 2015) as the consumers today are thorough consumers which means that consumers compare prices, read customer and product reviews and search for genuine content from real users and it is a very easy process for the consumers (Hafstrom et al., 2015). Conversely, today consumers are well informed and aware since consumers are encircled by advertising, social media, digital word of mouth, news articles and direct mailings that provide a wealth of information (Patel \& Puri, 2018). Adding up rises in the number and assortment of goods, retailing sector including mini and giant supermarket chain, online shopping and e- purchasing have expanded the area of consumer choice and complicated decision making (Hafstrom et al., 2015). Investigating consumer decision making styles are useful to determine consumer behaviors, segmenting the market and it provides a signal for marketers about the successes of their marketing strategies in modern marketing era. (Sprole \& Kendall, 1986; Bae, Pyun, \& Lee, 2010; Wanninayake, 2014).

Besides, in the modern marketing era, Millennial has become one of the major interesting research subjects (Mokhlis, 2009). Newly emerging generations of youth are called Millennials. Generally, Millennials are referred to as Generation Y or Generation Me (Bolton et al., 2013) but they are also labeled as generation tech, generation next, generation.com, generation 2000, echo boom, boom babies and Generation XX (Moreno, Lafuente, Avila, \& Moreno, 2017). Millennials are consumers born between 1980 and 2000 (Young \& Hinesly, 2012).

Today, researchers pay more attention to the millennial as a research subject due to the following reasons. First, millennial or generation $\mathrm{Y}$ is one of the most prominent demographic cohorts and age cohort to target for marketers. In addition to that, they stand for the largest generation in history (Bolton et al., 2013). There are approximately 1.8 billion millennial worldwide out of the 7.4 billion people, and it is anticipated that by 2025 Millennial will comprise three quarter of the world's workforce (Catalyzt, 2019). According to the Mid-Year Population Estimates by Department of Census and Statistics Sri 
Lanka (2018) approximately 6.6 million out of 22 million are millennial consumers. Second, they are moving into its leading spending years along with a huge indirect spending power due to their strong influence on their parents (Bolton et al., 2013). Nielsen report (2014) - "Sri Lanka 2013 review and opportunities in 2014" highlighted the characteristics of the Sri Lankan millennial. As per the report, millennials tend to be more optimistic than the average consumer as well as being a group with growing spending power. Furthermore, millennial is able to influence on other people's purchases and decisions (Mokhlis, 2009). Thirdly, Generation Y consumers attempt to establish their own identity through their own patterns of consumption which is based on their unique attitudes and beliefs of behavior (Mokhlis, 2009). Fourth fact is millennial are the first generation who spent their lives in the digital environment who are called "Digital Natives." These digital natives actively engage in social media platform activities such as shares, searches to consume content and works and plays (Bolton et al., 2013).

In spite of the above mentioned enthusiasm, several challenges have occurred within the manner of this potential marketing segment. In 2016, Future Research Company published a report titled "Marketing to Millennials" in which they explained unique characteristics of millennial. According to the report the digital fluency journey of Millennial is motivated by purpose. Generation $\mathrm{Y}$ is not inherently digital natives, unlike Generation Z, which we could identify as the world's first generation of real digital natives (Bolton et al., 2013; Nusair, Bilgihan, Okumus, \& Cobanoglu, 2013; Klapilova Krbova, 2016). Millennial have experienced pre internet world and easily adopted to post internet world too (Newman et al., 2016).The shopping environment of Millennials is a mix of digital and analogue markets and experiences (Newman et al., 2016). This generation still prefers to shop in brick-and-mortar stores. They want to touch, smell, and pick up the product (Donnelly \& Scaff, 2013) as well as do online shopping. According to the Goldman Sachs (2015) report, millennials generally tend not to be loyal customers (Newman et al., 2016), they are also quite price - sensitive (57\% of them compare prices) and actively seek value far beyond the power of premium brands. Even millennials do not want to be passive consumers but they rather want to actively participate, co-create, and be included as partners in the brands they love (Lantos, 2014). Online and mobile channels are important for millennials, as these channels provide information and insights to find the best products and services (Donnelly \& Scaff, 2013). Added, Nielsen report (2014) highlighted Sri Lankan millennial are fun - loving, adventurous, and they usually want their peers to move forward. Therefore, they are always on the lookout for the brands considered to be the most modern and trendy in this regard. They also love telling about their latest purchases to their peers, friends, and families - whether it's clothing or the latest technology gadget.

In summary, to investigate consumer decision-making, especially when it focuses on millennial decision-making, is more complex and difficult, but far more vital than in the past (Hafstrom, Chae, Chung, Hafstrom, \& Chae, 2015). The aim of this study is therefore to develop a more rigorous 
understanding of the millennial decision-making styles of Sri Lanka, while contributing to knowledge by filling following gaps in existing literature.

First, Hanzaee and Aghasibeig (2008) indicated that there is no universally recognized model for understanding consumer decision making styles. Hence consumer decision making styles differ across the cultures as evident by previous studies. Such as China (Chang, Hui, \& Wang, 2001), Iran (Hanzaee \& Aghasibeig, 2008), Malaysia (Mokhlis, 2009), India (Sharma \& Aich, 2012), Czech Republic (Wanninayake, 2015), Malaysia (Haron \& Chinedu, 2018). But the currently available decision making theories like "cue use theory", "Nicosia's buyer behavior mode" and "consumer typologies" are based mostly on Sproles and Kendall (1986) Consumer Style Inventory (CSI) theory (Haron \& Chinedu, 2018).

This study also adopted the same theory and scale which were developed by Sproles and Kendall in 1986. On the one hand, because, many scholars concluded that the original form of Consumer Style Inventory (CSI) needs to be reexamined in the context of different countries thus Consumer decision making styles differ across culture and cannot be generalized to the entire world (Haron \& Chinedu, 2018). On the other hand, literature on consumer decision making styles is based primarily on western cultures (Wang, Siu, \& Hui, 2014). But measurements of consumer decision making styles were developed for the Western countries might not apply equally in Sri Lanka until they have been tested and validated in the consumer context of the Sri Lankan market. Besides that, only very few studies have tried to investigate the consumer decision making styles in the Sri Lankan context (Dinesha, 2018). Therefore, this study works as a part of empirical studies of consumer decision - making styles conducted through a process for purifying, validating and applying consumer style inventory in the Sri Lankan context.

Second, although there were some researches about young consumer decision making styles (Hafstrom, Chae, \& Chung, 1992; Mokhlis, 2009), a very few of them focused on millennial context. Thereby, it is necessary to do a deep research on millennial decision making styles.

Further, consumer decision making styles have been studied over the latest few decades using various nationalities namely American, Korean ,Chinese, New Zealanders, Greek, Germans, British, South African and Turkish (Mokhlis, 2009). Although these studies have shown that consumer decision making style can be useful to international populations; Asian countries such as Sri Lanka do not know much about millennial decision - making styles. It is still not evident whether Sri Lankan millennial follows almost the same patterns of behavior as other consumers in other countries, or whether they have unique attributes when faced with market decisions. This study thus fills the gap by playing a pioneering role in examining Sri Lanka's millennial decision - making styles. 


\section{LITERATURE REVIEW}

\subsection{Consumer Decision-Making Style}

A consumer decision-making style is defined as "a mental orientation characterizing a consumer's approach to making choices" (Sprole and Kendall, 1986, p.268). Decision - making styles are vital for marketing due to several reasons. Firstly, it helps to determine consumer behaviour, are comparatively consistent over time and are therefore pertinent for market segmentation (Sprole \& Kendall, 1986). Secondly, marketers can understand cultural differences in the purchase (Wayne-Mitchell \& Walsh, 2001). Thirdly, it can be used for strategic marketing and effective communication activities (WayneMitchell \& Walsh, 2001). Fourthly, it can also be used as a consumer education tool and as a counseling device (Mitchell \& Bates, 2008). Finally, depending on the product and market these decision making styles may differ (Mitchell \& Bates, 2008).

As a result of this importance and complexity, numerous studies have attempted to develop the decisionmaking typologies. There are three (03) approaches to characterizing consumer decision making styles in the consumer literature.

a) The psychographic / lifestyle approach

b) The consumer typology approach

c) The consumer characteristics approach

However, consumer researchers have widely recognized the consumer characteristics approach as the most interpretative and strongest construct among these approaches as it focuses on a cognitive and an effective aspect of consumer behavior (Siu, Wang, Chang, \& Hui, 2006). In addition, this approach focuses on consumer mental orientation in decision making (Wanninayake, 2014).

In 1985, Sproles developed a tool for profiling consumer decision making styles in the context of consumer characteristics approach. It includes nine (9) hypothesized decision making style traits with fifty (50) items. Six consumer decision making style traits are identified and validated on the basis of the factor analysis. They are fashion conscious, economy conscious, socially conscious, Perfectionist, Satisfying orientation and time efficiency shopper. Nevertheless, the existing approach is not specifically designed to serve consumer-interest professionals. Therefore, in 1981, Sproles and Kendall further refined the existing inventory and developed a more logically consistent scale named Consumer Style Inventory (CSI). This refined inventory has been developed taking into account four criteria; it contains mental characteristics of a consumer's decision-making, the characterization complete as possible, identifying a small number of basic and independent consumer decision-making characteristics, the method measures how a consumer rates on each characteristic and the method includes measures important to consumer interest professionals (Sprole \& Kendall, 1986). Refined 
consumer style inventory is therefore used in the current study to identify the decision-making styles of the Sri Lankan millennial.

\subsection{Consumer Style Inventory (CSI)}

The CSI included 40 items on consumer decision making and measured the most basic eight (8) mental characteristics of consumer decision (Sprole \& Kendall, 1986). The characteristics/description of the eight styles of consumer decision making are shown in below

\section{\# $\quad$ Traits}

1 Perfectionist / High-quality conscious consumer

2 Brand conscious / 'Price equals quality" consumer

3 Novelty-fashion consciousness

4 Recreational / hedonistic shopping consciousness

\section{Characteristic /Description}

This type of consumers searches for the highest product quality. It could also be expected that those consumers who are higher in high quality conscious will shop more watchfully, more analytically and more systematically or by comparison. It is really hard to satisfy those consumers thus they are never satisfied with the "good enough" product.

These consumers are purchasing much more expensive well known premium brands. Consumers who are higher in brand conscious believe that better quality means a higher price. They also seem to prefer brands that are best-selling, mostly advertised.

Consumers who have scored high on this orientation is likely to gain enthusiasm and enjoy looking for new and fashionable things. They keep up with styles, and it's important for them to be in style. It also appears that variety - seeking is an important aspect of this characteristic. Further, these consumers are conscious of the new fashions and fads.

These consumers who fall into this orientation find shopping as enjoyable and are just shopping for fun. However, previous studies, label this orientation as a ' shopping avoider' thus negatively charging most items.

5 Price conscious/ "value for Those consumers are looking for selling prices and are generally money" shopping focus on lower prices, discounted or sale prices. Importantly, consciousness, 
they get the best value for their money for as well. They are likely to be shoppers for comparison.

6 Impulsiveness/ Careless consumer orientation

$7 \quad$ Confused by over choice consumer

8 Habitual / Brand-loyal consumer
These consumers are not very concerned about shopping and never plan their shopping. They also seem unconcerned about how much they spend or about the "best purchases."

These consumers perceive a lot of brands and stores to choose from and find it difficult to make choices. In addition, as several items in this factor imply, they experience information overload.

These consumers are likely to have favorite brands and habits of choice. Habitual behavior is the most well - known aspect of consumer decision - making, which strengthens its existence as a general feature

In an attempt to gain a deeper understanding of consumer decision making styles across different cultures, the Consumer Shopping Inventory (CSI) has been tested and validated in many countries However, many scholars have criticized the applicability and generalizability of the instrument for focusing solely on a student population that does not represent the whole consumer continuum from different demographics and cultures (Hafstrom et al., 1992; Wang et al., 2001; Haron \& Chinedu , 2018). But some findings of the studies are mostly consistent with findings of initial study of CSI (Hanzaee \& Aghasibeig, 2008).

\section{RESEARCH METHODOLOGY}

The present research adopted the positivism research paradigm thus it involves the use of existing theories such as consumer decision typologies, generational theory to develop hypotheses to be tested during the research process. The current study adopted a deductive research approach and a survey strategy. The mono method was chosen as a research method for the study, in which the researcher combined a single quantitative data collection technique, such as questionnaires, with quantitative data analysis procedures. (Saunders et al., 2009). A structured questionnaire was designed on the basis of the original CSI scale developed by Sproles and Kendall (1986) which included Forty (40) questions with a five-point scale: "strongly disagree (1), somewhat disagree, neither agree nor disagree, somewhat agree, strongly agree (5)." Eight (8) sub categories were included in questionnaire where seven (07) questions to measure perfectionist consciousness, three (03) questions for habitual, brand-loyal orientation, five (05) questions for novelty-fashion consciousness, six (6) questions for brand consciousness, five (5) questions for hedonistic shopping consciousness, four (4) questions for 
confusion from over choice, three (3) questions for price consciousness and five (5) questions for impulsiveness, have been included. Prior to the final survey a pilot test was conducted. The draft questionnaire was given to a few target respondents, as well as experts, to ensure the face validity of the research instrument. Accordingly, the questionnaire was redeveloped, and a pilot study was carried out using forty (40) respondents to pre - test the questionnaire in order to identify and eliminate potential problems. The pilot study helped to correct the questionnaire's weaknesses and distributed the finalized questionnaire for the final survey and it did not reveal any significant problems with the survey instrument and minor changes were produced to the questions on the basis of the responses received.

The proposed study can be considered as a single cross-sectional design and the sample of the study compromises of both males and females living in Sri Lanka who belong to the millennial generation. The researcher has used the non - probability sampling technique that the element in the population has no probability of being selected as sample subjects (Sekaran \& Bouige, 2018) and, convenience sampling technique was used to collect the sample from the population due to the unavailability of the sample frame. According to Krejcie \& Morgan (1970) table, a sample size of 384 is sufficient for a population size of more than 1,000,000. Therefore, 384 has been set as a sample size since the current study population is approximately 6.6 million (Mid-year Population Estimates by Department of Census and Statistics Sri Lanka., 2018).

\section{ANALYSIS}

The purpose of factor analysis of this section was to determine whether the consumer decision making styles recognized by prior researchers were common to the sample from the Sri Lankan Millennial. The appropriate method for factor analysis was then determined. The approach used to derive the weights or factor score coefficients differentiates the different factor analysis methods. There are two basic methods; Principle component analysis and Common factor analysis (Malhotra \& Dash, 2010). Present study adopted principle component analysis thus it considered the total variance in the data. Further, principle component analysis is recommended when the primary concern is to determine the minimum number of factors that will account for the maximum variance in the data for use in subsequent multivariate analysis by Malhotra and Dash (2010). In addition, from Sproles and Kendall (1986) to Haron and Chinedu (2018), all of the CSI's previous replications conducted principle component analysis to identify decision - making styles of the respondent.

Determine the number of factors next to the process of factor analysis. The various approaches, i.e., priori determination, based on eigenvalues, based on scree plot and based on percentage of variance are available to determine the number of factors. Among those, the study adopted based on eigenvalues combination with the percentage of variance. An eigenvalues symbolize the amount of variance 
associated with the factor. Therefore only factors are retained with a variance of eigenvalues greater than 1.0 (Malhotra \& Dash, 2010).

On the other hand, the percentage of variance extracted by the factors should reach a satisfactory level. It is recommended that at least 60 percent of the variance should be extracted by factor (Malhotra \& Dash, 2010). The Varimax procedure is used as a rotation method in this study, which minimizes the number of variable on a factor with high loads. This improves the interpretability of the factors (Malhotra \& Dash, 2010). Table 01 features varimax rotated factor loadings of the 40-item CSI for the sample of the Sri Lankan millennial.

Table 01: Rotated Component Matrix for CSI

\begin{tabular}{|c|c|c|c|c|c|c|}
\hline 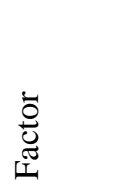 & 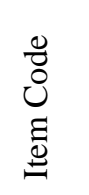 & Item & 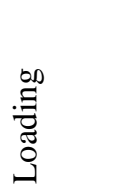 & 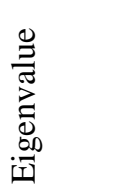 & 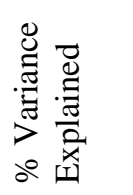 & 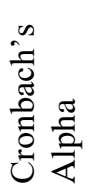 \\
\hline \multirow{6}{*}{ 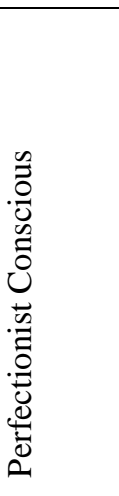 } & $\mathrm{PC} 1$ & $\begin{array}{l}\text { Getting very good quality is very important } \\
\text { to me. }\end{array}$ & .796 & \multirow{6}{*}{6.623} & \multirow{6}{*}{22.076} & \multirow{6}{*}{.824} \\
\hline & PC2 & $\begin{array}{l}\text { When it comes to purchasing products, I try } \\
\text { to get the very best or perfect choice }\end{array}$ & .816 & & & \\
\hline & PC3 & $\begin{array}{l}\text { In general, I usually try to buy the best } \\
\text { overall quality }\end{array}$ & .671 & & & \\
\hline & PC4 & $\begin{array}{l}\text { My standards and expectations for products } \\
\text { I buy are very high. }\end{array}$ & .676 & & & \\
\hline & PC5 & $\begin{array}{l}\text { I really give my purchases much thought } \\
\text { and care }\end{array}$ & .715 & & & \\
\hline & PC7 & $\begin{array}{l}\text { A product should be perfect, or the best, to } \\
\text { satisfy me. }\end{array}$ & .526 & & & \\
\hline \multirow{5}{*}{ 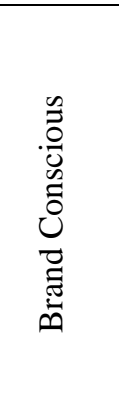 } & BF2 & $\begin{array}{l}\text { The more expensive brands are usually my } \\
\text { choice }\end{array}$ & .491 & \multirow{5}{*}{2.925} & \multirow{5}{*}{9.752} & \multirow{5}{*}{.828} \\
\hline & BF3 & $\begin{array}{l}\text { The most advertised brands are usually very } \\
\text { good choices. }\end{array}$ & .813 & & & \\
\hline & BF4 & $\begin{array}{l}\text { The higher the price of a product, the better } \\
\text { its quality. }\end{array}$ & .789 & & & \\
\hline & BF5 & $\begin{array}{l}\text { Nice department and specialty stores offer } \\
\text { me the best products. }\end{array}$ & .765 & & & \\
\hline & BF6 & I prefer buying the best-selling brands & .663 & & & \\
\hline \multirow{4}{*}{ 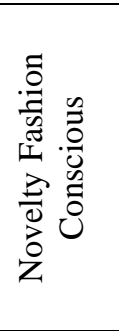 } & $\mathrm{NC} 1$ & $\begin{array}{l}\text { I keep my wardrobes up to date with the } \\
\text { changing fashions. }\end{array}$ & .689 & \multirow{4}{*}{2.201} & \multirow{4}{*}{7.335} & \multirow{4}{*}{.778} \\
\hline & $\mathrm{NC} 2$ & $\begin{array}{l}\text { I usually have one or more outfits of the } \\
\text { very newest style. }\end{array}$ & .831 & & & \\
\hline & NC3 & $\begin{array}{l}\text { Fashionable attractive styling is very } \\
\text { important to me. }\end{array}$ & .734 & & & \\
\hline & NC4 & $\begin{array}{l}\text { To get variety, I shop different stores and } \\
\text { choose different brands. }\end{array}$ & .638 & & & \\
\hline \multirow{2}{*}{ 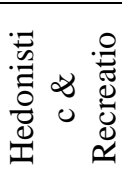 } & HR1 & Shopping is a pleasant activity for me & .874 & \multirow{2}{*}{1.966} & \multirow{2}{*}{6.554} & \multirow{2}{*}{.893} \\
\hline & HR2 & $\begin{array}{l}\text { Going shopping is one of the enjoyable } \\
\text { activities of my life. }\end{array}$ & .889 & & & \\
\hline
\end{tabular}




\begin{tabular}{|c|c|c|c|c|c|c|}
\hline & HR3 & I enjoy shopping just for the fun of it & .814 & & & \\
\hline \multirow{4}{*}{ 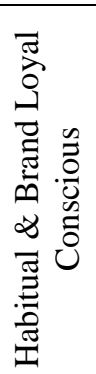 } & HB 1 & I have favorite brands I buy over and over & .690 & \multirow{4}{*}{1.502} & \multirow{4}{*}{5.005} & \multirow{4}{*}{.725} \\
\hline & HB2 & $\begin{array}{l}\text { Once I find a product or brand I like, I stick } \\
\text { to it }\end{array}$ & .752 & & & \\
\hline & HB3 & I go to the same store each time I shop & 697 & & & \\
\hline & BF1 & The well-known brands are best for me & .537 & & & \\
\hline \multirow{4}{*}{ 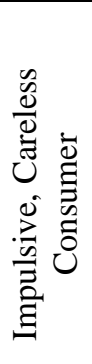 } & $\mathrm{IC} 1$ & $\begin{array}{l}\text { I should plan my shopping more carefully } \\
\text { than I do. }\end{array}$ & .634 & \multirow{4}{*}{1.476} & \multirow{4}{*}{4.920} & \multirow{4}{*}{.658} \\
\hline & IC2 & I am impulsive when purchasing & .754 & & & \\
\hline & IC3 & $\begin{array}{l}\text { Often I make careless purchases I later wish } \\
\text { I had not. }\end{array}$ & .695 & & & \\
\hline & IC5 & I do not carefully watch how much I spend. & .659 & & & \\
\hline \multirow{3}{*}{ 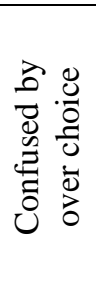 } & $\mathrm{CO} 2$ & $\begin{array}{l}\text { All the information I get on different } \\
\text { products confuses me. }\end{array}$ & .760 & \multirow{3}{*}{1.290} & \multirow{3}{*}{4.300} & \multirow{3}{*}{.675} \\
\hline & $\mathrm{CO} 3$ & $\begin{array}{l}\text { The more I learn about products, the harder } \\
\text { it seems to choose the best. }\end{array}$ & .776 & & & \\
\hline & $\mathrm{CO} 4$ & $\begin{array}{l}\text { Sometimes it's hard to choose which stores } \\
\text { to shop. }\end{array}$ & .722 & & & \\
\hline
\end{tabular}

Source: Survey Data

According to the results of rotated component matrix (Table 1), 29 items were loaded into 07 factors with a variance of eigenvalues greater than 1.0. Total variance of those factors was approximately $60 \%$. Table 16 results show that price value conscious has been removed and 7 factors remain out of 8 factors. Accordingly, researchers named the remaining factors in line with the original study conducted by Sproles and Kendall (1986) when reflecting similar decision - making characteristics

As per the results, six (6) out of the seven (7) items measured belonged to Perfectionist Consciousness, Four (4) out of the five (5) items that measured belonged to Novelty fashion consciousness, Three (3) out of five(5) items that measured indicated Hedonistic \& Recreational Consciousness, Three (3) out of four (4) items that measured read Confused by over choice, four (4) out of the five (5) items that measured showed Impulsive, Careless Consumer which in turn are consistent with original study conducted by Sproles and Kendall (1986).

Furthermore, it can be observed that some of the items loaded differently on factors apart from those mentioned by Sproles and Kendall (1986). For instance, an item in the original study of' Brand Consciousness was loaded in to the Habitual and Brand Loyal consciousness. However, that factor can be labeled as a habitual and brand loyal conscious thus it includes most of the brand loyal consumer characteristics. 
The findings of this study suggest that the Sri Lankan millennial has seven decision making styles, namely Perfectionist Consciousness, Habitual \& Brand Loyal Consciousness, Novelty Fashion Consciousness, Brand Consciousness, Hedonistic \& Recreational Consciousness, Confused by over choice and the Impulsive Consumer.

The descriptive statistics were calculated to further understand Sri Lanka's millennial decision - making styles.

Table 02: Descriptive Statistics of CSI

\begin{tabular}{|c|c|c|c|}
\hline \multicolumn{4}{|c|}{ Descriptive Statistics } \\
\hline CSI Dimensions & N & Mean & Std. Deviation \\
\hline Brand Conscious & 385 & 2.9938 & .69684 \\
\hline Impulsive Consumer & 385 & 3.2857 & .64134 \\
\hline Hedonistic \& Recreational Conscious & 385 & 3.3056 & .96485 \\
\hline Novelty Fashion Conscious & 385 & 3.4695 & .71184 \\
\hline Confused by over choice & 385 & 3.5152 & .66568 \\
\hline Habitual \& Brand Loyal Conscious & 385 & 3.6623 & .66336 \\
\hline Perfectionist Conscious & 385 & 4.1818 & .53857 \\
\hline
\end{tabular}

Source: Survey Data

The descriptive statics (Table 2) clearly indicate a high value under the Sri Lankan millennial highly perfectionist consciousness (Mean value $=4.182$ ). It indicated that Sri Lanka's millennial pursues the best quality as well as the best product choices. Further, they try to get the best value for money, they tend to monitor their expenditure and set a high standard of product expectations Moreover, they are willing to make special efforts to choose the very best product and services.

This finding also make it evident that the millennial in Sri Lanka has much less brand - conscious decision making style. It revealed that few Sri Lankan millennials prefer to purchase the best - selling and well - known brands compared to other decision - making styles.

\section{FINDINGS}

This study examines the applicability of the CSI to the Sri Lankan millennium that Sproles \& Kendall (1986) has introduced to measure consumer decision making styles. The findings of the present study showed that there are seven (7) major decision making styles among Sri Lankan Millennial: Perfectionist Consciousness, Brand consciousness, Novelty-fashion consciousness, Hedonistic \& Recreational Consciousness, Impulsive/ Careless Consumer, Confusion from over choice consumer and Habitual and Brand Loyal consciousness. While most items and dimensions are consistent with the 
original Sproles and Kendall (1986) study, it can be observed that some items were loaded differently.

For instance, an item; "The well-known brands are best for me" in the original study of' Brand Consciousness was loaded in to the Habitual and Brand Loyal consciousness. Due to the cultural differences between Sri Lanka and America, Millennial in Sri Lanka may interpret these issues differently. On the other hand, the different behavior of Sri Lankan consumers could be the reason behind this. For an example, Rathnayake (2015) identified that that some of the preferred brands are emotionally linked to young consumers and they prefer to remain loyal to those well-known brands.

The researcher compares the decision-making characteristics identified in this study and the results of six previous studies conducted in the USA, China, New Zealand, India and Malaysia.

Table 1: Consumer Style Inventory in Cross Cultural Perspective

\begin{tabular}{|c|c|c|c|c|c|c|c|c|c|c|c|c|}
\hline $\begin{array}{l}\text { Reference and } \\
\text { Country }\end{array}$ & 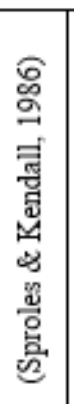 & 2 & 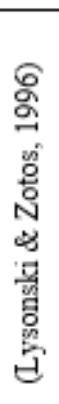 & 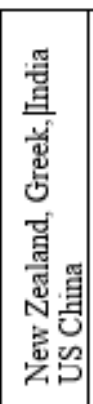 & 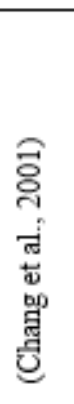 & 章 & 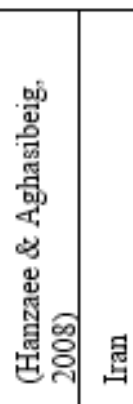 & 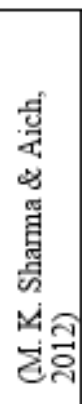 & 龺 & 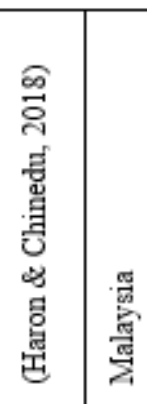 & 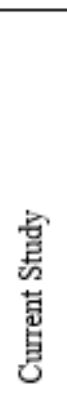 & 㓂 \\
\hline 1. Perfectionism & & Y & & I & & Y & $\mathrm{Y}$ & $\overline{7}$ & Y & $\mathrm{Y}$ & & Y \\
\hline $\begin{array}{ll}\text { 2. } & \begin{array}{l}\text { Brand } \\
\text { consciousness }\end{array} \\
\end{array}$ & & $\mathrm{Y}$ & & $I$ & & $\mathrm{Y}$ & $\mathrm{Y}$ & $\mathrm{I}$ & $Y$ & \multirow[b]{2}{*}{$\mathrm{Y}$} & & $\mathrm{Y}$ \\
\hline $\begin{array}{l}\text { 3. } \begin{array}{l}\text { Novelty- } \\
\text { fashion } \\
\text { consciousness }\end{array} \\
\end{array}$ & & $\mathrm{Y}$ & & $Y$ & & $\mathrm{Y}$ & $\mathrm{Y}$ & $\mathrm{I}$ & $Y$ & & & $\mathrm{Y}$ \\
\hline 4. Recreational & & $\bar{Y}$ & & I & 7 & $\overline{\mathrm{Y}}$ & $\mathrm{Y}$ & I & N & $\mathrm{Y}$ & & $\mathrm{Y}$ \\
\hline $\begin{array}{ll}\text { 5. } & \begin{array}{l}\text { Price } \\
\text { conscious }\end{array}\end{array}$ & & $\mathrm{Y}$ & & N & & $\mathrm{N}$ & $\mathrm{N}$ & $\mathrm{I}$ & $\mathrm{N}$ & $\mathrm{Y}$ & & $\mathrm{N}$ \\
\hline 6. Impulsiveness & & $\bar{Y}$ & & $Y$ & & N & $\mathrm{Y}$ & 1 & S & $\mathrm{N}$ & & $\mathrm{Y}$ \\
\hline $\begin{array}{l}\text { 7. } \begin{array}{l}\text { Confusion from } \\
\text { over choice }\end{array}\end{array}$ & & $\mathrm{Y}$ & & Y & 3 & $\mathrm{~N}$ & $\mathrm{Y}$ & $Y$ & Y & $\mathrm{Y}$ & & $\mathrm{Y}$ \\
\hline 8. Habitual & & $\mathrm{Y}$ & & $Y$ & & N & $\mathrm{Y}$ & 1 & $\mathrm{~N}$ & $\mathrm{Y}$ & & $\mathrm{Y}$ \\
\hline
\end{tabular}

Source: Original from the Researcher

In 1996, Lysonski and Zotos, published a paper titled "Consumer Decision-Making styles: A MultiCountry Investigation" in which they described the inventory which seems to be more applicable to the more developed countries than to the developing countries. The differences in the retail environment in the developing countries may explain why the inventory cannot be applied to, unless the instrument is modified (Lysonski \& Zotos, 1996).

However, interestingly, this is contrary to a study conducted by Wang et al.(2001) in the Chinese context. Using confirmatory factor analysis, the CSI dimensions were re - examined and validated by author. The findings show that, four styles of decision - making are relatively stable namely 
perfectionistic, brand conscious, novelty-fashion conscious and recreational. It is suggested that the CSI is to be applied to different cultures but the price conscious factor needs to be redeveloped.

With the same objective, a study was conducted by Hanzaee and Aghasibeig (2008) in Iran. The finding of this study is mostly consistent with the findings of the initial study of CSI.Without price consiouesness all the other factors are equal to the original scale.

The second major finding of the study is, Price conscious decision making style did not appear among the Sri Lankan Millennial. There are few possible reasons why Sri Lankan Millennials are not price conscious. First, Bakewell and Mitchell (2003) mentioned that millennials are less likely to be price conscious. Some Millennials still depend on their parents. Their parents are giving money to millennial to buy the product and services that they need. Hence, they are less likely to be price conscious when they purchase since they have not yet experienced how difficult it is to earn money (Musika ,2018).This is in good agreement with the results of the present study since majority of the sample are still undergraduate who depend on their parents $(71 \%)$. Second, those undergraduates, who represent the millennial generation have received some generous allowances such as mahapola, bursary, apart from parental income and perhaps a part - time job, that may also be a reason for being less price conscious. Third, as highlighted by Mamun, Rahman, and Robel (2014) innovators or early adopters seem to be less price sensitive than later buyers. Since millennials are early adopters as per the previous literature (Lingelbach, Patino, \& Pitta, 2012), this could also be one of the reasons why they are not price conscious. Fourth, as Rathnayake (2015) points out, the Sri Lankan millennial has a strong emotional connection with some brands and tends to be loyal to that brand. Therefore, it could lead to less price consciousness, thus brand loyal consumers are less price sensitive (Mamun et al., 2014). Fifth, The Sri Lankan millennials in particular are highly perfectionist, which is evident from the findings of the present study. These perfectionist consumers may be willing to pay premium prices for the best quality (Hanzaee \& Aghasibeig, 2008 ${ }^{\mathrm{a}}$.

Besides, this finding is consistent with findings of past studies by Lysonski and Zotos (1996) in New Zealand, Wang, Chang, and Hui (2001) in China; Hanzaee and Aghasibeig (2008) in Iran ;Sharma and Aich (2012) in India. They also point towards the non-appearence of the price conscious decision making style in their countries as well. Moreover, some scholars argued that the price - conscious construct had some criticisms of its reliability. Hence it needed refinement or rebuilding the price conscious construct (Chang et al., 2001).

The perfectionist conscious decision making style found in this study had the highest loads and highest mean value. The finding is consistent with findings of past studies by Mokhlis (2009) which identified perfectionist consciousness as top style among Indian, Korean, the Chinese and the U.S. consumers. Further, this is one of the unchanging decision making style confirmed in a number of previous studies. (Sproles \& Kendall, 1986; Lysonski \& Zotos, 1996; Wang et al., 2001; Hanzaee \& Aghasibeig, 2008a; 
Sharma \& Aich, 2012; Wang et al., 2014; Haron \& Chinedu, 2018). Moreover, Kalhoro, Khan, and Mehmood (2012) observed that most asian consumers would like European or American products to have better quality and further revealed that quality is the most important element that concerns the millennial when they make a purchase.

This was followed by the Habitual and Brand Loyal conscious decision making style which marked the second highest mean value (3.6623). Such consumers constantly form the habits of choosing a specific brand or buying from the same store (Haron \& Chinedu, 2018). Moreover, regardless of market prices, they are brand loyalists. This finding is in the lines of above mentioned finding; Price conscious decision making style did not appear among the Sri Lankan millennial. In addition, millennial consumers spend more on branded products, including status products, to maintain their status ; they will stay with those brands that convey status as long as the status effect lasts (Kalhoro et al., 2012). Moreover, a study titled "Relationship Between Millennials and Brand Loyalty: Mediating Brand Loyalty Factors" conducted by Kalhoro et al. (2012) found that Superior service, Use of advertisements, Customer Trust, Use of social media, Quality products and services and Overall company mission mediate the positive relationship between millennials and brand loyalty. Good practice of these factors by Sri Lankan marketers may be the reasons behind the highly habitual type of consumers

Conversely, these results were contradicted by the studies of Ordun (2015) and Moreno, Lafuente, \& Carreón (2017) who considered millennial consumers as a disloyal segment. It shows that Sri Lankan's millennial consumer characteristic differs from globally defined millennial consumers.

\section{THEORETICAL AND PRACTICAL IMPLICATIONS}

The findings from this study make several noteworthy contributions to the current literature. First, many scholars have argued that the original form of the Consumer Style Inventory (CSI) needs to be reexamined in the context of different countries ( Wang, Siu, \& Hui, 2014; Wanninayake, 2015). Further, very few studies have attempted to investigate the Sri Lankan decision making styles. Completing this gap, the present study examines the applicability of the CSI to the Sri Lankan millennium introduced by Sproles \& Kendall (1986) to measure styles of consumer decision - making. The findings of this study showed that Sri Lankan Millennial has seven (7) major decision - making styles. There are Perfectionist Consciousness, Brand consciousness, Novelty-fashion consciousness, Hedonistic \& Recreational Consciousness, Impulsive/ Careless Consumer, Confusion from over choice consumer and Habitual and Brand Loyal consciousness. However, price value consciousness has been removed from the model and the study found that price conscious decision making style did not exist among the Sri Lankan millennial. Further, study revealed that the perfectionist conscious decision making style had the highest loads and highest mean value followed by Habitual and Brand 
consciousness. These findings enhance our understanding of the Sri Lankan millennial decision making styles.

This study's practical contribution focused primarily on marketing managers. The management could gain a perspective on the most efficient customer analysis based on the findings. Further, they could apply those insights to more marketing applications. The findings of this research will have valuable implications for the marketing mix and it could be used in different ways by marketers.

First, the findings of this study help marketers in better understanding the decision-making styles of Sri Lankan millennials. As a result, the CSI validated by a researcher is an appropriate tool for analyzing the behavior of millennial consumers in Sri Lanka. In addition, having a reliable and valid tool helps creating consumer profile to guide marketing strategy.

Second, the current study's findings assist consumer researchers and educators better understand millennial decision-making styles, and they could be used as a guideline for consumer decision-making styles in Sri Lankan consumer education.

Third, they can utilize the findings of the research to segmentation, targeting and positioning. Fourth, study revealed that the perfectionist conscious decision-making style had the highest loads and highest mean value followed by Habitual and Brand Consciousness. Marketers can therefore take advantage of this perfectionist feature by focusing on quality, functionality and efficiency as considering this as a unique selling proposition of their product or service when they are targeting the millennial. Further, they can use this feature to differentiate their product and services. Not only that, they can use market experts to communicate a product of high quality, prestige, and self-esteem (Betti \& Jahandad, 2016). Since, Millennials highly focus on brand, marketers should focus on brand image of the product and service that they marketed. Hence, marketers should involve with brand building and development activities in order to attract more Millennials.

\section{LIMITATIONS AND FURTHER RESEARCH}

The study had several limitations that should be taken into account when assessing the findings and implications of the study. First, the study was restricted to the millennial consumers in Sri Lanka. Consequently, different results may be obtained if the study is conducted in other generations. Future studies may consider including a more heterogeneous group of respondents with different generations, helping to draw stronger and more generalized conclusions. Furthermore, Self - administered questionnaires were used to collect data from the millennium Thus, these respondents may have given highly subjective responses. 


\section{REFERENCES}

Bae, S., Pyun, D., \& Lee, S. (2010). Consumer Decision-Making Styles for Singaporean College Consumers: An Exploratory Study. ICHPER-SD Journal of Research, 5(2), 70-76.

Bakewell, C., \& Mitchell, V. W. (2003b). Generation Y female consumer decision-making styles. International Journal of Retail \& Distribution Management, 31(2), 95-106. https://doi.org/10.1108/09590550310461994

Bolton, R. N., Parasuraman, A., Hoefnagels, A., Migchels, N., Kabadayi, S., Gruber, T.,Solnet, D. (2013). Understanding generation $\mathrm{Y}$ and their use of social media; a review and research. Journal of Service Management, 24(3), 245-267.

Catalyst. (2019, November 07). Quick Take: Generations-Demographic Trends in Population and Workforce . Retrieved from Catalyst: https://www.catalyst.org/research/generations-demographic-trends-in-populationand-workforce/

Chang, L. M. K., Hui, A. S. Y., \& Wang, C. (2001). Adapting Consumer Style Inventory to Chinese Consumers : A Confirmatory Factor Analysis Approach. Journal of International Consumer marketing, 13(2), 29-47. https://doi.org/10.1300/J046v13n02

Donnelly, C., \& Scaff, R. (2013). Who are the Millennial shoppers? And what do they really want?

Goldman_Sachs,(2015)._ Millennials_ Retrieved From Goldman Sachs: https://www.goldmansachs.com/insights/archive/millennials/

Hanzaee, K. H., \& Aghasibeig, S. (2008a). Generation Y female and male decision-making styles in Iran : Are they different? The International Review of Retail, Distribution and Consumer Research, 18(5), 521-537. https://doi.org/10.1080/09593960802573443

Haron, S. A., \& Chinedu, A. H. (2018). Consumer Background and Decision Making Styles of Malaysian College Students. International Journal of Business and Management, 13(1), 170-182. https://doi.org/10.5539/ijbm.v13n1p170

Kalhoro, S. H., Khan, F. S., \& Mehmood, R. W. (2012). consumers' Decision Making Styles of Mobile Phone Purchases Among University Level Students in Pakistan. Sri Lankan Journal of Management, 17(JulyDecember).

Lantos, G. P. (2014). Marketing to Millennials: Reach the Largest and Most Influential Generation of Consumers Ever. Marketing and American Consumer Culture, 101-110. https://doi.org/10.1007/978-3-319-47328-4_11

Lingelbach, D., Patino, A., \& Pitta, D. A. (2012). The emergence of marketing in Millennial new ventures. Journal of Consumer Marketing, 29(2), 136-145. https://doi.org/10.1108/07363761211206384.

Lysonski, S., \& Zotos, Y. (1996). Consumer decision-making styles: a multi-country. European Journal of Marketing, 30(12), 10-21. https://doi.org/10.1108/03090569610153273

Malhotra, N., \& Dash, S. (2010). Marketing Research: An Applied Orientation (sixth). Pearson Education Limited.

Mamun, A. Al, Rahman, M. K., \& Robel, S. D. (2014). A critical review of consumers' sensitivity to price: Managerial and theoretical issues. Journal of International Business and Economics, 2(2), 1-9.

Mitchell, \& Bates, L. (2008). UK Consumer Decision-Making Styles. Journal of Marketing Management, 14(13), 199-225. https://doi.org/10.1362/026725798784959345 
Mokhlis, S. (2009). An Investigation of Consumer Decision-Making Styles of Young-Adults in Malaysia. International Journal of Business and Management, 4(4), 140-148.

Moreno, F. M., Lafuente, J. G., Avila, F., \& Moreno, S. M. (2017). The Characterization of the Millennials and Their Buying Behavior. International Journal of Marketing Studies, 9(5), 135-144. https://doi.org/10.5539/ijms.v9n5p135

Moreno, F. M., Lafuente, J. G., \& Carreón, F. Á. (2017). The Characterization of the Millennials and Their Buying Behavior. International Journal of Marketing Studies, 9(5), 135-144. https://doi.org/10.5539/ijms.v9n5p135

Newman, D., Blanchard, O., \& Kramer, S. (2016). Marketing To Millennials. Futurum Research, Llc.

Nielsen. (2014). Sri Lanka: 2013 In Review And Opportunities In 2014. Colombo: Nielsen: Sri Lanka.

Ordun, G. (2015). Millennial (Gen Y) Consumer Behavior, Their Shopping Preferences and Perceptual Maps Associated With Brand Loyalty. Canadian Social Science, 11(4), 40-55. https://doi.org/10.3968/6697

Patel, N., \& Puri, R. (2018). To understand consumer psychology. Retrieved from https://www.quicksprout.com/the-complete-guide-to-understand-customer-psychology-chapter-1/

Rathnayake, D. T. (2015). Emotional Brand Attachment And Brand Loyalty: Empirical Evidences From Sri Lankan Smart Phone Industry. In 1st' Annual International Conference on Branding \& Advertising -2015 (p. $10)$.

Schiffman, L., Hansen, H. \& Kinuk, L. (2007). Consumer Behavior: A European Outlook”, . Pearson Education. https://doi.org/10.1016/b978-0-7506-7897-1.00013-3

Sekaran, U., \& Bouige, R. (2018). Research Methods for Business:A Skill Building Approach (7th ed.). Wiley India Pvt Ltd.

Sharma, M. K., \& Aich, S. (2012). Consumer Shopping Decision Making Styles at Departmental Stores : An Exploratory Study of Gender DifferenceS. Indian Journal of Commerce \& Management Studies, III(2), 5157.

Sproles, G. B., \& Kendall, E. L. (1986). A Methodology for Profiling Consumers ' Decision-Making Styles. The Journal of Consumer Affairs, 20(2), 267-289.

Wang, C., Siu, N. Y. M., \& Hui, A. S. Y. (2014). Consumer decision-making styles on domestic and imported brand clothing. European Journal of Marketing, 38(1.5), 239-252. https://doi.org/10.1108/03090560410511212

Wanninayake, W. M. C. B. (2015). Consumer Decision-Making Styles and Local Brand Biasness : Exploration in Consumer Decision-Making Styles and Local Brand Biasness : Exploration in the Czech Republic. Journal of Competitiveness, 6(1), 3-17. https://doi.org/10.7441/joc.2014.01.01

Wayne-Mitchell, V., \& Walsh, G. (2001b). Consumers' decision-making style as a basis for market segmentation Thorsten Hennig-Thurau. Journal of Targeting, Measurement and Analysis for Marketing, 10(2), 117-131. https://doi.org/10.1057/palgrave.jt.5740039

Young, A. M., \& Hinesly, M. D. (2012a). Identifying Millennials' key influencers from early childhood: Insights into current consumer preferences. Journal of Consumer Marketing, 29(2), 146-155. https://doi.org/10.1108/07363761211206393 